\title{
BMJ Open Acute ischaemic stroke outcomes following mechanical thrombectomy in the elderly versus their younger counterpart: a retrospective cohort study
}

\author{
Mark R Villwock, Amit Singla, David J Padalino, Eric M Deshaies
}

To cite: Villwock MR, Singla A, Padalino DJ, et al. Acute ischaemic stroke outcomes following mechanical thrombectomy in the elderly versus their younger counterpart: a retrospective cohort study. BMJ Open 2014;4:e004480. doi:10.1136/bmjopen-2013004480

- Prepublication history for this paper is available online. To view these files please visit the journal online (http://dx.doi.org/10.1136/ bmjopen-2013-004480).

Received 15 November 2013 Revised 17 February 2014 Accepted 27 February 2014

CrossMark

Department of Neurosurgery, SUNY Upstate Medical University, Syracuse, New York, USA

Correspondence to Dr Eric M Deshaies; DeshaieE@upstate.edu

\section{ABSTRACT}

Objectives: Many physicians debate the efficacy of mechanical thrombectomy for ischaemic stroke, but most agree that to establish potential benefit, patient selection must be examined further. People $>80$ years are a growing population of patients with ischaemic stroke but are largely excluded from clinical trials. The benefit of thrombectomy for them may be greatly reduced due to diminishing neuroplasticity and a larger number of medical comorbidities. To address this knowledge gap, we examined clinical and economic outcomes after mechanical thrombectomy in the ischaemic stroke population from the Nationwide Inpatient Sample. Our null hypotheses were that elderly patients (>80 years) would have a similar rate of inpatient mortality in comparison to their younger counterparts and incur a similar economic expense.

Design: Retrospective cohort study.

Setting: A 20\% stratified sample of US community hospitals within the Nationwide Inpatient Sample.

Participants: All patients from 2008 to 2010 with a primary diagnosis of ischaemic stroke that received mechanical thrombectomy were included.

Primary and secondary outcome measures:

The primary outcome was inpatient mortality. Secondary outcomes included hospital charges and length of stay.

Results: Less than $1 \%$ of all ischaemic stroke cases (9300) were treated with mechanical thrombectomy. Of these, $18 \%$ involved patients over 80 years of age. The odds of inpatient mortality in elderly patients treated with mechanical thrombectomy were approximately twice that of their younger counterparts (OR1.993, $p<$ $0.001)$. The elderly experienced no significant difference in hospital charges $(p=0.105)$ and length of stay $(p=0.498)$.

Conclusions: The odds of inpatient mortality after mechanical thrombectomy in patients over 80 years of age were twice that of their younger counterparts.

This is consistent with the overall worse prognosis seen in the natural history of this age group. Studies to better identify patients that would benefit from endovascular mechanical thrombectomy may improve outcomes and reduce the gap currently observed in age stratifications.

\section{Strength and limitations of this study}

- The large number of included patients and the ability to study medical practice at large without selection bias.

- Owing to limitations in the database we could not control for disease specifics in each population such as location/size of occlusion, collateral reperfusion, blood glucose level and admission National Institutes of Health Stroke Scale (NIHSS) score.

- The time period of the study predated the arrival of stent-retriever devices, which may prove to be safer and more efficacious than previous generation devices.

\section{INTRODUCTION}

Controversy over the utility of endovascular mechanical thrombectomy (EMT) for acute ischaemic stroke (AIS) has arisen since the Interventional Management of Stroke III trial (IMS III) was stopped in 2012 because of statistical futility. ${ }^{1}$ Two additional trials, MR-RESCUE and SYNTHESIS Expansion, similarly failed to show any significant benefit with EMT for AIS. ${ }^{1-3}$ Although individuals may disagree on the conclusions and debate the limitations of these trials, most agree that better selection criteria need to be established in order to identify potential subpopulations of patients who may benefit from EMT for AIS. Additionally, the costeffectiveness of this intervention must be assessed and weighed in comparison with clinical outcomes. This is particularly important with the rise of healthcare costs in the USA, which at its current pace is expected to reach one-fifth of the gross domestic product by $2018 .{ }^{4}$ Early debates of the Affordable Care Act centred on the creation of death panels to ration expenses. Although this panel was dismissed as myth, there remains a critical need to analyse the cost of newly developed stroke interventions in an ageing 
population that may not incur the same benefits as their younger peers due to lack of neuroplasticity and ongoing medical comorbidities.

The elderly population is expected to grow dramatically over the coming decades, specifically with the percentage of persons over 80 years of age doubling by $2050 .^{5}$ Given the growing percentage of elderly and their growing life expectancy, discussions regarding procedural risk versus clinical benefit will expand in importance, particularly with regard to costly interventions like EMT. The paucity of data on EMT, specifically in the elderly population, limits the physician's ability to adequately counsel patients and their families regarding any potential benefit from this emergent intervention.

To address this knowledge gap, we examined the elderly ischaemic stroke population treated with EMT in a national database. Our null hypotheses were that elderly patients ( $>80$ years) would have a similar rate of inpatient mortality in comparison with their younger counterparts and incur a similar economic expense. The primary outcome was inpatient mortality. Secondary outcomes included hospital charges and length of stay.

\section{METHODS}

We analysed discharge data from the Nationwide Inpatient Sample (NIS), Healthcare Cost and Utilization Project (HCUP), Agency for Healthcare Research and Quality (Rockville, Maryland, USA). This database represents approximately a $20 \%$ stratified sample of US community hospitals. Detailed information on the design of the NIS is available at http://www.hcup-us.ahrq.gov. We examined the prevalence of EMT for AIS using data published from NIS for 2008-2010.

Patients with AIS were identified in the NIS using the International Classification of Diseases, 9th Revision, Clinical Modification (ICD-9-CM) codes (433.01, 433.11, $433.21,433.31,433.81,433.91,434.01,434.11,434.91$ and 437.1). Intervention utilising EMT was identified using the ICD-9-CM procedure code 39.74, and pharmacological thrombolysis was documented with procedure code 99.10. Of note, there is no distinction in the ICD-9-CM code between intra-arterial and intravenous administration of thrombolytics. Additionally, a hospital was classified as 'high volume' if its total discharge stroke volume exceeded 147 cases/year. ${ }^{6}$ Total hospital charges from 2008 to 2009 were compounded yearly at an inflation rate of $3 \%$ to standardise the charges at 2010 levels. The length of hospital stay and associated hospital charges were calculated for all patients (including in-hospital deaths) and additionally for surviving patients. The second analysis was conducted to examine the economic measures without the artificial shortening of these variables that may occur in cases of comfort rather than curative care. The comorbidity burden of each patient was expressed as the sum of the Elixhauser comorbidity measures. ${ }^{78}$
Data were analysed using SPSS V.17 (IBM Corporation, Armonk, New York, USA). To obtain national estimates, discharge weights were applied. Univariate comparisons were performed using Mann-Whitney $\mathrm{U}$ tests and $\chi^{2}$ tests, as appropriate.

Binary logistic regression was used to analyse the primary objective, inpatient mortality. The analysis considered the following factors known to affect stroke outcome: elderly age ( $>80$ years), thrombolysis administration, presentation to a 'high-volume' stroke centre, gender and All Patient Refined-Diagnosis Related Group (APR-DRG) severity of illness (SOI). Backward stepwise regression was performed with variable entry when probability was less than 0.05 and removal when probability exceeded 0.10 . ORs and their 95\% CIs were reported.

Generalised linear models with a $\gamma$-distribution and $\log$ link function were used to analyse the economic measures. The exponential parameter estimates were reported along with their 95\% CIs. The exponential parameter estimates are equivalent to the ratio of the estimated marginal means with the denominator being the reference category. A probability value of 0.01 was considered statistically significant in order to nominally control for type I error.

\section{RESULTS}

Nationally, there were 1674200 AIS cases during the years 2008-2010, $9300(<1 \%)$ of which received EMT. Overall inpatient mortality for AIS was $7.9 \%$. This rate increased to $23.8 \%$ when considering only patients receiving intervention with EMT. Patients greater than 80 years of age receiving EMT had an inpatient mortality rate of $33.7 \%$, significantly exceeding the rate for their younger counterpart that was found to be $21.6 \%$ ( $p<0.001$; table 1$)$. In comparison with younger patients, the patient over 80 was more likely to be a Caucasian woman on Medicare, to have received pharmacological thrombolysis and to not be discharged home (table 1). Interestingly, no patients, young or elderly, treated at low-volume stroke centres were discharged home $(0 / 70)$. This is opposed to $10.8 \%$ of patients admitted to high-volume stroke centres $(\mathrm{p}=0.004)$.

Multivariate analysis was performed to examine the primary and secondary outcome measures (figure 1). The odds for inpatient mortality in the elderly treated with EMT were approximately double in comparison with their younger counterpart (OR 1.993, 95\% CI 1.763 to $2.254, \mathrm{p}<0.001)$. The factors noted to significantly $(\mathrm{p}<.01)$ reduce mortality were presentation to a high-volume stroke centre $(\mathrm{OR}=0.378)$, thrombolysis administration $(\mathrm{OR}=0.873)$, female gender $(0.855)$ and decreased SOI (figure 1). There was no significant difference in hospital charges and length of stay for the elderly (figure 1). The economic measures were most influenced by SOI (figure 1).

\section{DISCUSSION}

The paucity of data on EMT in the elderly impedes the ability of physicians and patients to make informed 
Table 1 Patient-level and hospital-level characteristics of the population receiving mechanical thrombectomy for acute ischaemic stroke compared between the elderly and their younger counterpart

\begin{tabular}{|c|c|c|c|}
\hline & $\leq 80$ years $(n=7614$ cases $)$ & $>80$ years $(n=1686$ cases $)$ & p Value \\
\hline Age & $63(53-73)$ & $84(82-87)$ & \\
\hline Gender, female & $46.9 \%$ & $66.7 \%$ & $<0.001$ \\
\hline Race, Caucasian & $60.2 \%$ & $67.6 \%$ & 0.013 \\
\hline \multicolumn{4}{|l|}{ Median income level } \\
\hline$<$ US\$39000 & $26.7 \%$ & $23.5 \%$ & \multirow[t]{4}{*}{0.607} \\
\hline US\$39 000-\$47999 & $24.8 \%$ & $25.6 \%$ & \\
\hline US\$48 000-\$62 999 & $23.6 \%$ & $23.5 \%$ & \\
\hline$\geq$ US $\$ 63000$ & $24.9 \%$ & $27.4 \%$ & \\
\hline Payer, Medicare & $44.9 \%$ & $90.5 \%$ & $<0.001$ \\
\hline \multicolumn{4}{|l|}{ Elixhauser comorbidity score } \\
\hline$\leq 2$ & $37.2 \%$ & $30.6 \%$ & \multirow[t]{3}{*}{$<0.001$} \\
\hline 3 & $21.7 \%$ & $26.5 \%$ & \\
\hline$\geq 4$ & $41.1 \%$ & $42.9 \%$ & \\
\hline \multicolumn{4}{|l|}{ APR-DRG severity of illness } \\
\hline Mild & $0 \%$ & $0 \%$ & \multirow[t]{4}{*}{0.418} \\
\hline Moderate & $1.5 \%$ & $0.6 \%$ & \\
\hline Major & $53.5 \%$ & $53.9 \%$ & \\
\hline Extreme & $45 \%$ & $45.5 \%$ & \\
\hline Thrombolysis (intravenous or intra-arterial) & $55.5 \%$ & $63.1 \%$ & 0.013 \\
\hline Length of stay, days (survivors) & $9(5-14)$ & $9(6-13.6)$ & 0.711 \\
\hline Length of stay, days (all patients) & $8(4-13)$ & $8(4-12)$ & 0.004 \\
\hline Total charges, US\$ (survivors) & 137692 (95 139-207 687) & 137756 (87 582-198 103) & 0.021 \\
\hline Total charges, US\$ (all patients) & 132828 (90 661-205 835) & 126238 (86 230-188 294) & $<0.001$ \\
\hline Discharged home & $12.7 \%$ & $2.1 \%$ & $<0.001$ \\
\hline Inpatient mortality & $21.6 \%$ & $33.7 \%$ & $<0.001$ \\
\hline \multicolumn{4}{|l|}{ Hospital owner } \\
\hline Government, non-federal & $22.6 \%$ & $18.8 \%$ & \multirow[t]{3}{*}{0.150} \\
\hline Private, non-profit & $69.2 \%$ & $74.6 \%$ & \\
\hline Private, investor-owned & $8.2 \%$ & $6.6 \%$ & \\
\hline Teaching hospital & $84.2 \%$ & $80.6 \%$ & 0.122 \\
\hline
\end{tabular}

decisions. As this segment of the population is forecasted to dramatically increase, additional information on the risk versus benefit of intervention will facilitate physician-patient discussions.

This study quantifies clinical and economic outcomes following EMT for AIS in patients older than 80 years of age across the USA. The higher mortality in patients aged over 80 years is in agreement with the overall worse prognosis seen in the natural history of this age group. For example, the Specialized Program of Translational Research in Acute Stroke (SPOTRIAS) examined patients $\geq 80$ years of age who received intravenous $\mathrm{rt}-\mathrm{PA}$ and/or intra-arterial therapy. ${ }^{9}$ The database contained more than 1100 patients aged 80 years and greater. It documented a higher risk of in-hospital mortality for the elderly patient with stroke (OR 2.13), but no difference in mortality rates between intervention modalities. Similarly, data from the European BIOMED Study of Stroke Care Group and the Safe Implementation of Thrombolysis in StrokeMonitoring Study (SITS-MOST) registry reported outcomes from patients with AIS aged >80 years, and documented higher mortality and worse functional outcomes. $^{10} 11$ Specifically, the SITS-MOST registry documented an increase in mortality by $18 \%$ for patients $>80$ years and a $22 \%$ reduction in independence. ${ }^{11}$

It is reassuring to note that the population of elderly patients in the present study exhibited similar mortality in comparison to the above-mentioned thrombolysis trials. Patients in the current study were all treated with EMT, likely for one of two reasons: (1) failure of intravenous rt-PA to clear a proximal large vessel occlusive lesion or (2) the individual arrived to the hospital after a prolonged time lapse from symptom onset, thereby leaving EMT as the last line of therapy within the accepted time windows. Both of these indications represent a group of exceptionally disease burdened patients.

The role of gender in stroke outcomes is not clearly defined. In agreement with our study, Saposnik et $a l^{12}$ reported on 12262 patients with AIS and noted the male sex to be a predictor of early mortality. Yet, Niewada et $a l^{13}$ reported the results of 17370 patients with AIS and documented that women had higher 14-day and 6-month mortality; while Adams et $a l^{14}$ collected data on 1281 patients with AIS and found no 


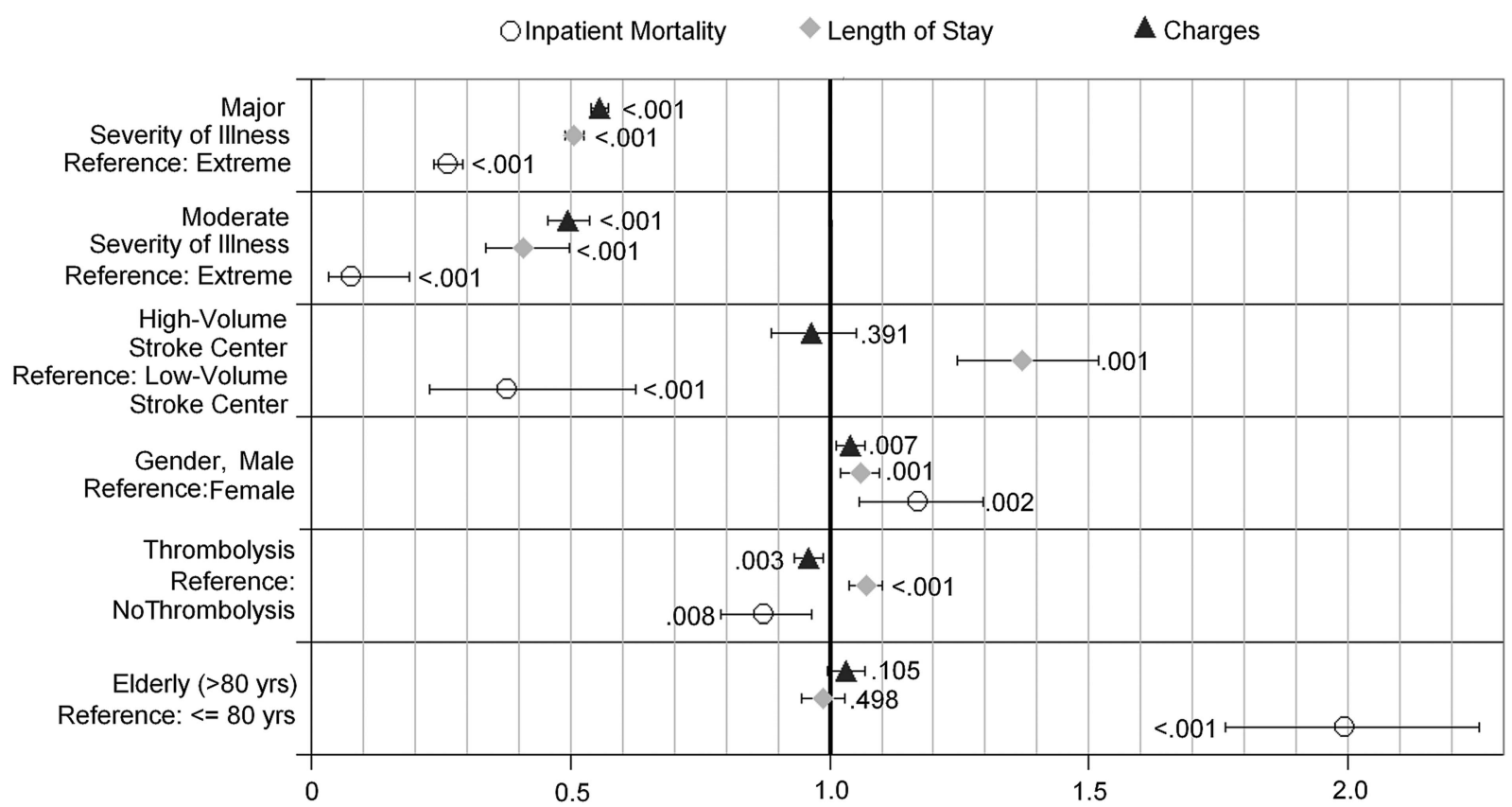

Figure 1 Multivariate analysis of inpatient mortality and economic measures for survivors. Inpatient mortality expressed as the OR along with the $95 \% \mathrm{Cl}$ derived from binary logistic regression. Length of stay and charges are both expressed using the exponential parameter estimate along with the $95 \% \mathrm{Cl}$ derived from generalised estimating equations. $p$ Values are adjacent to the $95 \%$ Cls. Points to the right of 1.0 reflect an increase in the odds/effect ratio relative to the indicated reference category. Points to the left of 1.0 reflect a decrease in the odds/effect ratio relative to the indicated reference category.

relationship between outcome and gender. Further research is warranted to investigate any gender effects with regard to patients with AIS, and specifically those undergoing EMT.

We anticipated increased expenses for the elderly with regard to their overall inpatient admission due to the larger number of chronic conditions, higher morbidity burden and diminished efficiency of rehabilitation. ${ }^{15} 16$ It was surprising to note no significant differences in the economic measures based on age for survivors. If deaths were included, the length of stay and hospital charges were reduced in the elderly population. We believe largely due to increased utilisation of comfort rather than curative measures in the elderly population as evident by their increased rate of in-hospital mortality. Additionally, we must point out that our analysis does not reflect the true societal cost. ${ }^{17-19}$ Long-term rehabilitation and care should be considered in future studies, but these measures were beyond the scope of the anonymised database used in this study.

Owing to limitations in the NIS we could not further investigate disease specifics in each population such as location/size of occlusion, collateral reperfusion, blood glucose level and admission National Institutes of Health Stroke Scale (NIHSS) score. ${ }^{20-22}$ These variables are known to affect stroke outcome and the distribution within each population is unknown. While this is a limitation of the analysis, it is common to any large database study, and the benefits of large database examination include the ability to study medical practice at large without selection bias. An additional limitation is that the primary and secondary objectives do not include any specific neurological or functional assessment, as these are not recorded in the NIS. Discharge to home was not considered as a primary objective as this variable may be influenced by the payor status and social factors, rather than a true assessment of independence and self-care. Lastly, the data collected for NIS predates the arrival of stent-retriever devices, which may prove to be safer and more efficacious than previous generation devices.

\section{CONCLUSION}

EMT for patients with AIS older than 80 years of age resulted in significantly increased inpatient mortality in comparison to their younger counterparts. This is consistent with the overall worse prognosis seen in the natural history of this age group. Studies to better identify patients that would benefit from EMT may improve outcomes and reduce the gap currently observed in age stratifications. Ongoing endeavours to develop new revascularisation devices may also improve AIS outcomes after EMT.

Contributors EMD and MRV contributed to the study concept and design. MRV took part in the acquisition of the data. MRV, AS, DJP and EMD participated in the analysis and interpretation of the data. MRV and EMD were involved in the drafting of the manuscript. AS and DJP performed the critical revision of the manuscript for important intellectual content. EMD is the guarantor.

Funding This research received no specific grant from any funding agency in the public, commercial or not-for-profit sectors. 
Competing interests EMD is a physician consultant for MicroVention, Covidien Neurovascular, Integra LifeSciences Corporation and McKesson Health Solutions.

Ethics approval This study used the Nationwide Inpatient Sample, a de-identified patient database. Therefore, this study did not require IRB review in accordance with the Code of Federal Regulations, 45 CFR 46.

Provenance and peer review Not commissioned; externally peer reviewed.

Data sharing statement Data were generated from the Nationwide Inpatient Sample, a publicly available database. There are no additional data available.

Open Access This is an Open Access article distributed in accordance with the Creative Commons Attribution Non Commercial (CC BY-NC 3.0) license, which permits others to distribute, remix, adapt, build upon this work noncommercially, and license their derivative works on different terms, provided the original work is properly cited and the use is non-commercial. See: http:// creativecommons.org/licenses/by-nc/3.0/

\section{REFERENCES}

1. Broderick JP, Palesch YY, Demchuk AM, et al. Endovascular therapy after intravenous t-PA versus t-PA alone for stroke. $N$ Engl $J$ Med 2013;368:893-903.

2. Ciccone A, Valvassori L, Nichelatti M, et al. Endovascular treatment for acute ischemic stroke. N Engl J Med 2013;368:904-13.

3. Kidwell CS, Jahan R, Gornbein J, et al. A trial of imaging selection and endovascular treatment for ischemic stroke. $N$ Engl J Med 2013;368:914-23.

4. Office of the Actuary in the Centers for Medicare and Medicaid Services. NHE projections 2008-2018. Centers Medicare Medicaid Serv. http://www.cms.hhs.gov/nationalhealthexpenddata/downloads/ proj2008.pds (accessed 13 Feb 2013)

5. Vincent G, Velkoff V. The next four decades, the older population in the United States: 2010 to 2050: Current Population Reports. US Census Bur 2010. https://www.census.gov/prod/2010pubs/p25-1138. pdf (accessed 18 Mar 2014)

6. Kimball MM, Neal D, Waters MF, et al. Race and income disparity in ischemic stroke care: Nationwide Inpatient Sample Database, 2002 to 2008. J Stroke Cerebrovasc Dis 2014;23:17-24.

7. Elixhauser A, Steiner C, Harris DR, et al. Comorbidity measures for use with administrative data. Med Care 1998;36:8-27.

8. Vogel TR, Dombrovskiy VY, Haser PB, et al. Outcomes of carotid artery stenting and endarterectomy in the United States. J Vasc Surg 2009;49:325-30; discussion 330.

9. Willey JZ, Ortega-Gutierrez S, Petersen N, et al. Impact of acute ischemic stroke treatment in patients $>80$ years of age: the specialized program of translational research in acute stroke (SPOTRIAS) consortium experience. Stroke 2012;43:2369-75.

10. Di Carlo A, Lamassa M, Pracucci G, et al. Stroke in the very old clinical presentation and determinants of 3-month functiona outcome: a European perspective. European BIOMED Study of Stroke Care Group. Stroke 1999;30:2313-19.

11. Ford GA, Ahmed N, Azevedo E, et al. Intravenous alteplase for stroke in those older than 80 years old. Stroke 2010;41:2568-74.

12. Saposnik G, Kapral MK, Liu Y, et al. IScore: a risk score to predict death early after hospitalization for an acute ischemic stroke. Circulation 2011;123:739-49.

13. Niewada M, Kobayashi A, Sandercock PAG, et al. Influence of gender on baseline features and clinical outcomes among 17,370 patients with confirmed ischaemic stroke in the international stroke trial. Neuroepidemiology 2005;24:123-8.

14. Adams HP Jr, Davis PH, Leira EC, et al. Baseline NIH Stroke Scale score strongly predicts outcome after stroke: a report of the Trial of Org 10172 in Acute Stroke Treatment (TOAST). Neurology 1999;53:126-31.

15. Popa-Wagner A, Carmichael ST, Kokaia Z, et al. The response of the aged brain to stroke: too much, too soon? Curr Neurovasc Res 2007;4:216-27.

16. Alemayehu $\mathrm{B}$, Warner KE. The lifetime distribution of health care costs. Health Serv Res 2004;39:627-42.

17. Dewey HM, Thrift AG, Mihalopoulos C, et al. Cost of stroke in Australia from a societal perspective: results from the North East Melbourne Stroke Incidence Study (NEMESIS). Stroke 2001;32:2409-16.

18. Kolominsky-Rabas PL, Heuschmann PU, Marschall D, et al. Lifetime cost of ischemic stroke in Germany: results and national projections from a population-based stroke registry-the Erlangen Stroke Project. Stroke 2006;37:1179-83.

19. Lee WC, Christensen MC, Joshi AV, et al. Long-term cost of stroke subtypes among medicare beneficiaries. Cerebrovasc Dis 2007;23:57-65.

20. Costalat V, Lobotesis $\mathrm{K}$, Machi $\mathrm{P}$, et al. Prognostic factors related to clinical outcome following thrombectomy in ischemic stroke (RECOST Study). 50 patients prospective study. Eur J Radiol 2012;81:4075-82.

21. Ishkanian AA, McCullough-Hicks ME, Appelboom G, et al. Improving patient selection for endovascular treatment of acute cerebral ischemia: a review of the literature and an external validation of the Houston IAT and THRIVE predictive scoring systems. Neurosurg Focus 2011;30:E7.

22. Natarajan SK, Dandona $\mathrm{P}$, Karmon $\mathrm{Y}$, et al. Prediction of adverse outcomes by blood glucose level after endovascular therapy for acute ischemic stroke. $J$ Neurosurg 2011;114:1785-99. 